\title{
An epigenetic vaccine model active in the prevention and treatment of melanoma A Nazmul H Khan ${ }^{1}$, William J Magner ${ }^{1}$ and Thomas B Tomasi*1,2
}

Address: ${ }^{1}$ Laboratory of Molecular Medicine, Department of Immunology, Roswell Park Cancer Institute, Buffalo, NY, USA and ${ }^{2}$ Departments of Medicine and Microbiology \& Immunology, School of Medicine and Biomedical Sciences, State University of New York, Buffalo, NY, USA

Email: A Nazmul H Khan - anmnazmul.khan@roswellpark.org; William J Magner - william.magner@roswellpark.org; Thomas B Tomasi* - thomas.tomasi@roswellpark.org

* Corresponding author

Published: 10 December 2007

Journal of Translational Medicine 2007, 5:64 doi:10.I 186/1479-5876-5-64
Received: 17 October 2007

Accepted: 10 December 2007

This article is available from: http://www.translational-medicine.com/content/5/I/64

(c) 2007 Khan et al; licensee BioMed Central Ltd.

This is an Open Access article distributed under the terms of the Creative Commons Attribution License (http://creativecommons.org/licenses/by/2.0), which permits unrestricted use, distribution, and reproduction in any medium, provided the original work is properly cited.

\begin{abstract}
Background: Numerous immune genes are epigenetically silenced in tumor cells and agents such as histone deacetylase inhibitors (HDACi), which reverse these effects, could potentially be used to develop therapeutic vaccines. The conversion of cancer cells to antigen presenting cells (APCs) by HDACi treatment could potentially provide an additional pathway, together with crosspresentation of tumor antigens by host APCs, to establish tumor immunity.

Methods: HDACi-treated B 6 melanoma cells were used in a murine vaccine model, lymphocyte subset depletion, ELISpot and Cytotoxicity assays were employed to evaluate immunity. Antigen presentation assays, vaccination with isolated apoptotic preparations and tumorigenesis in MHCdeficient mice and radiation chimeras were performed to elucidate the mechanisms of vaccineinduced immunity.

Results: HDACi treatment enhanced the expression of MHC class II, CD40 and B7-I/2 on BI6 cells and vaccination with HDACi-treated melanoma cells elicited tumor specific immunity in both prevention and treatment models. Cytotoxic and IFN- $\gamma$-producing cells were identified in splenocytes and $\mathrm{CD} 4^{+}, \mathrm{CD} 8^{+} \mathrm{T}$ cells and NK cells were all involved in the induction of immunity. Apoptotic cells derived from $\mathrm{HDACi}$ treatments, but not $\mathrm{H}_{2} \mathrm{O}_{2}$, significantly enhanced the effectiveness of the vaccine. HDACi-treated BI6 cells become APCs in vitro and studies in chimeras defective in cross presentation demonstrate direct presentation in vivo and short-term but not memory responses and long-term immunity.

Conclusion: The efficacy of this vaccine derives mainly from cross-presentation which is enhanced by HDACi-induced apoptosis. Additionally, epigenetic activation of immune genes may contribute to direct antigen presentation by tumor cells. Epigenetically altered cancer cells should be further explored as a vaccine strategy.
\end{abstract}

\section{Background}

Modified tumor cells can induce tumor-specific immunity and, in certain models, activate both adaptive and innate immune responses [1]. However, in some mouse models and the vast majority of human cancers, the tumor vaccines currently employed have not been successful. This may be attributed to a failure of adequate stimulation of appropriate components of immunity and/or tolerance to 
tumor antigens [2]. In general, tumor vaccination strategies have focused on enhancing a cytotoxic T cell (CTL) response. Activation of both T-helper cells and CTLs is achieved primarily through cross-presentation of tumor antigens by professional antigen presenting cells (APCs) [2]. Antigens from apoptotic cells have been reported to be a preferred vehicle for activating tumor immunity, rather than tolerance, through cross-presentation by APCs $[1,3]$. Direct antigen presentation by tumor cells could potentially activate $\mathrm{T}$ cells provided the tumor cells can deliver an MHC-restricted antigen-specific signal together with appropriate costimulatory signals [4-6]. However, the role of tumor cells as APCs has not been well defined. Nevertheless, MHC class I mediated direct priming of CTLs has been observed in an engineered tumor model which is dependent on the density of MHC/peptide complexes and the expression of B7 costimulatory molecules on tumor cells [7]. Moreover, transfection of MHC class II negative tumors with MHC class II and B7-1 genes produces a cellular vaccine capable of eliciting immunity [8]. MHC class II positive tumor cells are also effective APCs in vivo and can present novel endogenous antigenic peptides not presented by host APCs [5]. Furthermore, transfection of tumors with class II transactivator (CITA) elicits MHC class II expression and can restore the ability of certain tumor cells to present antigen and induce immunity $[9,10]$. Although cross-presentation is the major mechanism generating immunity [2,3], the above studies on tumors as APC suggest that, at least in certain tumors, direct antigen presentation could provide an alternative or additional pathway in tumor immunity. An important issue is whether direct presentation can be enhanced in vivo and become a quantitatively significant component of tumor immunity.

Tumor escape has been attributed to selection of tumor cells with mutations in genes involved in both the initiation and effector phases of immunity [11]. Recent evidence also suggests that tumor cells may exploit epigenetic silencing of immune genes to escape immune destruction [12]. Epigenetic repression of immune genes in tumors was first suggested for MHC class II genes and CD40, which are infrequently mutated although often deficient in tumors [13]. A number of other immune genes, including MHC class I, components of the class I peptide presentation pathway (TAP1, TAP2, LMP2, LMP7 and Tapasin), B7-1/2, NKG2D ligands and certain tumor antigens, are also silenced by chromatin in multiple tumor types $[12,14]$.

Covalent modifications of chromatin are well established regulators of gene expression and an array of epigenetic alterations, including acetylation and methylation, have been shown to target histones [15]. Histone acetylation induced by histone deacetylase inhibitors (HDACi) fre- quently increases accessibility of transcription factors to promoter sites and results in enhanced gene transcription, although some genes are inhibited by HDACi. The HDACi trichostatin A (TSA) regulates the expression of $\sim 5 \%$ of the genome [16]. HDACi treatments have been used in clinical trials on the basis of their ability to induce differentiation and apoptosis of tumor cells [17]. HDACi-treated tumor cells have also been successfully employed in a murine tumor vaccine model [4]. Reversal of gene silencing by HDACi treatment can convert a plasma cell tumor to an APC, in vitro, through upregulation of MHC class II and costimulatory molecules [4,18]. Moreover, HDACi treated melanoma tumor cells can mediate direct antigen presentation via MHC class I, which stimulates IFN- $\gamma$-producing $\mathrm{T}$ cells in vitro [14]. The present study was constructed to determine the mechanisms involved in immunity generation by TSA-treated melanoma vaccines and whether this epigenetically modified tumor cell vaccine is effective in a treatment model.

\section{Materials and methods Cells, mice and reagents}

Mouse B16 melanoma, EL4 thymoma cell lines and hybridoma GK1.5, 2.43 and 53-6.7 cells (ATCC, Manassas, VA) were maintained in culture as specified. Six to eight week old female C57BL/6 (B6) (NCI, Bethesda, MD), MHC class I deficient B6.129- $\beta_{2} \mathrm{~m}^{\text {tm } 1}$ [class $\left.\mathrm{I}^{-/-}\right]$, class II deficient

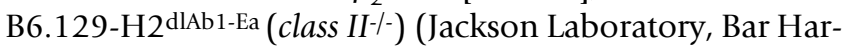
bor, ME), class I and class II double deficient B6.129$\mathrm{A} \beta \beta^{\mathrm{tm} 1}-\beta_{2} \mathrm{~m}^{\mathrm{tm} 1}$ (class $\mathrm{I}^{-} /-\mathrm{II}^{-} /$) (Taconic, Germantown, NY) and ovalbumin-specific $\mathrm{I}^{\mathrm{A}} \mathrm{A}^{\mathrm{b}}$-restricted TCR transgenic (OT-II) (Protul Shrikant, RPCI, Buffalo, NY) mice were maintained in the Department of Laboratory Animal Resources at RPCI. Principles of laboratory animal care (NIH publication 85-23, revised 1986) were followed and all work was carried out under RPCI IACUC approval. TSA (Wako Biochemical, Richmond, VA), $\mathrm{H}_{2} \mathrm{O}_{2}$ (Sigma, St. Louis, MO) and mouse IL-2 (R\&D System, Minneapolis, $\mathrm{MN}$ ) were diluted in ethanol, water and PBS containing $0.5 \%$ BSA, respectively.

\section{Flow cytometry}

R-Phycoerythrin conjugated anti-mouse I-A ${ }^{\mathrm{b}}, \mathrm{H}-2 \mathrm{D}^{\mathrm{b}}$, CD4, CD40, CD80, CD86 and Pan-NK (DX5), FITC conjugated anti-mouse $\mathrm{I}^{\mathrm{b}} \mathrm{b}$ and CD3, PE-Cy5.5 conjugated anti-mouse CD8 and CD11c mAb, isotype controls matched to each antibody (Pharmingen, San Diego, CA) and FITC conjugated annexinV (Caltag, Burlingame, CA) were used in flow cytometry experiments as previously described [4]. The gated cell populations included both apoptotic and non-apoptotic cells. In all preparations utilized here, the adherent cells studied were $>95 \%$ viable by trypan blue exclusion. 


\section{Tumorigenesis assays}

TSA-treated or untreated B16 cells $\left(1 \times 10^{5}\right.$ trypan blue negative adherent cells) were injected s.c. in the ventral trunk of the mice. This tumor challenge dose is 10 fold higher than the minimum number of untreated cells required to generate palpable tumor in $100 \%$ of mice within 3 weeks after injection. Treated cells were assayed prior to injection to ensure consistency between experiments in MHC and costimulatory molecule expression as well as apoptosis. Tumors were measured every 3 days and mice were euthanized when tumor diameter reached 1 $\mathrm{cm}$. After 40 days, all tumor-free mice were re-challenged s.c. with untreated B16 $\left(1 \times 10^{5}\right)$ cells in the opposite site and observed for another 60 days. In addition to palpable tumor measurement, the absence of evidence of tumor in immune mice was confirmed by visual inspection. At the end of the study period (100 days after vaccination), a mouse from each group of tumor-free mice was euthanized and the tumor inoculation sites and regional lymph nodes dissected and examined for evidence of tumor (no visible tumor nodule or other evidence of tissue aberration) and compared with a palpable tumor-bearing mouse (visible tumor nodules in lymph nodes). Some tumor-free B6 mice were re-challenged with EL4 $\left(1 \times 10^{4}\right)$ cells simultaneously as a control for tumor specificity. For the treatment model, B6 mice bearing palpable ( $~ 0.5$ $\mathrm{mm}$ ) B16 tumor, 5 days after s.c implantation in the trunk, were vaccinated with TSA- treated and irradiated (2000 Gy) B16 cells in the opposite side. Groups of tumor-bearing control mice received irradiated B16 cells or were left untreated. Mice that became tumor-free were re-challenged 42 days latter with wild type B16 in the trunk and observed for another 40 days.

\section{Cytotoxicity assays}

To determine tumor immunity, tumor-free mice, 30 days after vaccination with TSA-treated B16 cells, were re-challenged with untreated B16 cells and observed for an additional 15 days. Spleens isolated from three immune or control mice were disrupted and splenocytes were purified over nylon wool (Polyscience, Warrington, PA). Nonadherent lymphocytes $\left(5 \times 10^{5}\right)$ were re-stimulated with TSA-treated (500 nM for $48 \mathrm{~h}$ ) and irradiated (200 Gy) tumor cells $\left(2.5 \times 10^{5}\right)$ in RPMI-1640 with IL-2 (10 U/ $\mathrm{ml})$. After 4 days, T-cell-enriched (>90\%) viable cells were isolated after centrifugation through Ficoll-Paque and the level of anti-B16 cytotoxicity was determined utilizing a standard $4.5 \mathrm{~h}{ }^{51} \mathrm{Cr}$-release assay [4].

\section{ELISpot assays}

The mouse IFN- $\gamma$ ELISpot kit (BD Bioscience, San Diego, CA) was used to determine antigen specific IFN- $\gamma$-secreting cells in spleens of immune mice as described [19]. Briefly, RBC-depleted splenocytes $\left(1 \times 10^{6}\right.$ cells/well $)$ isolated from immune and control mice were incubated in triplicate wells with B16 tumor cell lysate $\left(\sim 8 \times 10^{4}\right.$ cell lysate/well) or $5 \mu \mathrm{M}$ mgp $100_{25-33}$ peptide (Invitrogen, Grand Island, NY) for $24 \mathrm{~h}$. IFN- $\gamma$ spots were developed with AEC substrate and counted using a Zeiss Imaging system. B6 mice bearing palpable tumor 15 days after inoculation of untreated B16 $\left(1 \times 10^{5}\right.$ cells $)$ and naïve mice were used as controls. Splenocytes $\left(2 \times 10^{5}\right.$ cells/well $)$ from naïve mice treated with PMA $(40 \mathrm{ng} / \mathrm{ml})$ and Ionomycin $(1 \mu \mathrm{M})$ served as positive control. For in vitro antigen presentation assays, popliteal lymph node T cells $(2 \times$ $10^{5}$ ), isolated from ovalbumin-primed OT-II mice and purified magnetically (Pan T cell isolation kit, Miltenyi, Auburn, CA), were assayed in triplicate with TSA-treated $(500 \mathrm{nM}$ for $48 \mathrm{~h})$ or untreated B16 cells $\left(1 \times 10^{5}\right)$ for 24 h. Splenocytes isolated from OT-II mice were used as control APCs. Tumor cells and splenocytes were pulsed with ova-peptide 322-338 or the control E333A ova-peptide $322-$ ${ }_{338}(10 \mu \mathrm{M})$ and irradiated (2000 Gy and $30 \mathrm{~Gy}$ respectively) before use in the ELISpot assays to measure IFN- $\gamma$ secreting T cells.

\section{In vivo depletion studies}

Anti-CD4 (GK1.5) and CD8 (2.43) hybridomas were grown i.p. in SCID mice and ascites fluid was partially purified by ammonium sulfate precipitation. To deplete $\mathrm{CD}^{+}{ }^{+}$or CD8+ $\mathrm{T}$ cells, $\mathrm{B} 6$ mice were injected i.p. with CD4 or CD $8 \mathrm{mAb}(200 \mu \mathrm{g}$ in $200 \mu \mathrm{l}$ PS/mouse), given at day $-2,0,+2,+4,+8$ and +14 . Rabbit anti-asialoGM1 $\gamma$-globulin (Wako), reconstituted in water and diluted in PBS, was used for NK cell depletion using the same schedule. Control mice received purified rat IgG (Chemicon International, Temecula, CA). Control and depleted mice were vaccinated with TSA-treated B16 cells after the $2^{\text {nd }}$ dose of antibody injection and observed for 30 days. Depletion was assessed on the day of vaccination and a week later by flow cytometric analysis of splenocytes for $\mathrm{CD} 3{ }^{+} \mathrm{CD} 4{ }^{+}$, $\mathrm{CD}^{+}{ }^{+} \mathrm{CD} 8+\mathrm{T}$ cells and DX5 ${ }^{+} \mathrm{NK}$ cells.

\section{Bone marrow chimera generation}

Bone marrow (BM) cells were harvested from femur and tibia of groups of donor (B6 and class $\mathrm{I}^{-/-} \mathrm{-I} /-$ ) mice by flushing the bones with RPMI-1640. RBCs were lysed using Tris-buffered ammonium chloride and single cell suspensions were obtained by passing BM cells through a cell strainer [20]. T cells were depleted from BM preparations by incubation with CD8 (53-6.7) and CD4 (GK 1.5) $\mathrm{mAb}\left(1: 10\right.$ dilution) for $60 \mathrm{~min}$ at $4^{\circ} \mathrm{C}$, followed by lysis with low-tox-M rabbit complement (Cederlane, Ontario, Canada) for $90 \mathrm{~min}$ at $37^{\circ} \mathrm{C}$ in $5 \% \mathrm{CO}_{2}$ incubator [21]. In preliminary experiments, $\mathrm{BM}$ cells after treatment with hybridoma supernatants (53-6.7 or GK1.5) were analyzed by flow cytometry using CD3, CD4 (L3T4) and CD8 (5H10) mAb to confirm the depletion of $\mathrm{CD}^{+}{ }^{+} \mathrm{CD} 4^{+}$or $\mathrm{CD} 3{ }^{+} \mathrm{CD} 8{ }^{+} \mathrm{T}$ cells. One day before $\mathrm{BM}$ infusion, recipient B6 mice were injected i.p. with a single dose anti- 
asialoGM1 ( $20 \mu \mathrm{l}$ in $200 \mu \mathrm{l}$ sterile PBS) antibody to prevent NK mediated rejection of $\mathrm{BM}$. The recipient mice were exposed to 11 Gy total body irradiation (TBI) administered in two treatments $3 \mathrm{~h}$ apart from a ${ }^{137} \mathrm{Cs}$-radiation source on the day of BM infusion. A total of $5 \times 10^{6} \mathrm{BM}$ cells from donor mice were injected into the tail vein of each recipient. Chimeras were provided with water containing $2 \mathrm{mg} / \mathrm{ml}$ neomycin sulfate for 4 weeks after irradiation. Splenocytes, isolated from irradiated mice 2 days after TBI, were analyzed by flow cytometry to confirm the elimination of $\mathrm{CD} 11 \mathrm{c}^{+}$APCs and CD3+ ${ }^{+}$cells and $>99 \%$ elimination was observed. To obtain a dendritic cell (DC) enriched APC population, low-density splenocytes were isolated by collagenase digestion [22]. At 4-8 weeks after BM transplant, chimerism was evaluated using PBLs and splenocytes isolated from chimeric mice.

\section{Isolation of apoptotic tumor cells}

Apoptotic B16 cells were isolated using annexinV microbead kit, MS separation column and magnetic separator (Miltenyi, CA) according to the manufacturer's protocol. Briefly, TSA or $\mathrm{H}_{2} \mathrm{O}_{2}$-treated B16 cells were labeled with annexinV microbead for $15 \mathrm{~min}$ at $6-12{ }^{\circ} \mathrm{C}$ and passed through a separation column in a magnetic field. AnnexinV positive $\left(\mathrm{an}^{+}\right)$apoptotic cells were retained in the column while annexinV negative (an-) non-apoptotic cells ran through. Apoptotic cells were eluted after removal of the column from the magnetic field.

\section{Results}

Enhanced expression of MHC class II and costimulatory molecules on melanoma cells after TSA treatment

Previously we showed that TSA treatment elicits the expression of MHC class II and costimulatory molecules on the mouse plasma cell tumor J558 and that vaccination with epigenetically altered tumor cells generates tumor-specific immunity [4]. To extend this to another tumor and to further analyze the mechanisms involved in immunity generation we used the MHC class II negative B16 melanoma. To determine the cell surface expression of MHC class I, class II, CD40, CD80 and CD86 in relation to apoptosis induction, TSA-treated $(50 \mathrm{nM}-1 \mu \mathrm{M}$, $12-48 \mathrm{~h}$ ) adherent ( $95 \%$ viable) B16 cells were analyzed by flow cytometry. The conditions inducing maximal expression are presented in Figure 1A. This Figure demonstrates enhancement of the expression of MHC class II, CD40 and CD86 on B16 cells at $24 \mathrm{~h}$ and $48 \mathrm{~h}$ of TSA treatment. TSA treatment also slightly enhanced the lowlevel expression of class I found on untreated cells. Treatment with $500 \mathrm{nM}$ TSA for $48 \mathrm{~h}$, a condition that produced $46 \% \mathrm{an}^{+}$cells in the adherent B16 population, in addition to class II, CD40 and CD86 induced low-level expression of CD80. TSA-treated B16 cells retained enhanced expression of these genes over $24 \mathrm{~h}$ after withdrawal of treatment in vitro (data not shown). These results demonstrate that TSA treatment induces apoptosis and elicits expression of class II and costimulatory molecules on B16 tumor cells similar to the results previously reported on the J558 plasmacytoma [4].

\section{Durable immunity generated by epigenetically altered melanoma cell vaccination}

To determine whether TSA treatment altered tumorigenicity and immunogenicity, B16 cells treated with different concentrations of TSA were inoculated into mice. As shown in Table 1, nearly all control and $90 \%$ of the 250 nM TSA treated B16 ( $20 \%$ an $^{+}$cells) injected mice developed tumors. Using $500 \mathrm{nM}$ TSA $(24 \mathrm{~h})$ treated B16 ( $40 \% \mathrm{an}^{+}$cells), $30 \%$ of the mice injected were tumorfree for more than 40 days. However, when mice were inoculated with B16 cells treated with $500 \mathrm{nM}$ TSA for 48 $\mathrm{h}\left(\sim 50 \% \mathrm{an}^{+}\right.$cells), $80 \%$ of the mice were tumor-free after 10 days, by which time all controls had developed tumors, and more than $60 \%$ of the mice remained tumorfree for over 40 days (Table 1 and Figure 1B). When tumor-free immune mice were re-challenged with untreated B16, 100\% of the TSA-treated B16 vaccinated mice showed lasting immunity (Figure 1C). The immunity generated by TSA-treated B16 vaccination is tumor specific as the unrelated EL4 thymoma developed tumor in $100 \%$ of the immune mice (data not shown). In similar experiments, B16 cells treated with high dose $(750 \mathrm{nM}$ for $48 \mathrm{~h})$ TSA, containing $\sim 90 \% \mathrm{an}^{+}$cells, demonstrated immunity in $40 \%$ of the mice after vaccination (data not shown). This high dose was associated with greater number of $\mathrm{an}^{+}$cells did not improve the effectiveness of the vaccine. These results indicate that, similar to the TSAtreated plasmacytoma vaccine, TSA-treated melanoma cells generate immunity and preparations containing approximately $50 \% \mathrm{an}^{+}$cells were most effective in inducing tumor specific lasting immunity [4].

\section{Induction of cytotoxic and IFN- $\gamma$ secreting lymphocytes in immune mice}

To determine whether CTLs were elicited in immune mice, T-cell-enriched splenic lymphocytes were isolated from TSA-treated B16-vaccinated mice that remained tumor-free after re-challenge and assessed for their ability to lyse untreated B16 cells. As shown in Figure 2A, splenic lymphocytes derived from immune mice displayed substantial B16 lytic activity (26\%) compared with splenocytes derived from control mice $(<2 \%)$ at an effector: target ratio 50:1. The cytotoxic lymphocytes induced by TSA-treated melanoma vaccination were tumor specific, since lysis of the unrelated target EL4 (1\%) was significantly lower than that of B16 (Figure 2A).

ELISPOT assays were employed to measure IFN- $\gamma$ production by cytotoxic lymphocytes from immune mice. As shown in Figure 2B, splenocytes derived from mice immu- 


\section{A)}

$\mathbf{I}-\mathbf{A}^{\mathbf{b}}$
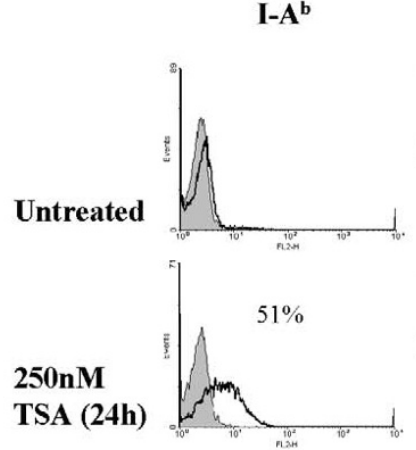

TSA (24h)

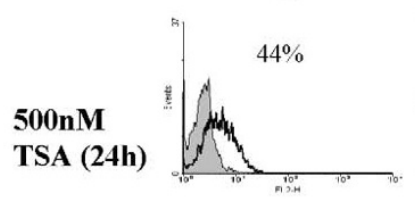

TSA (24h)
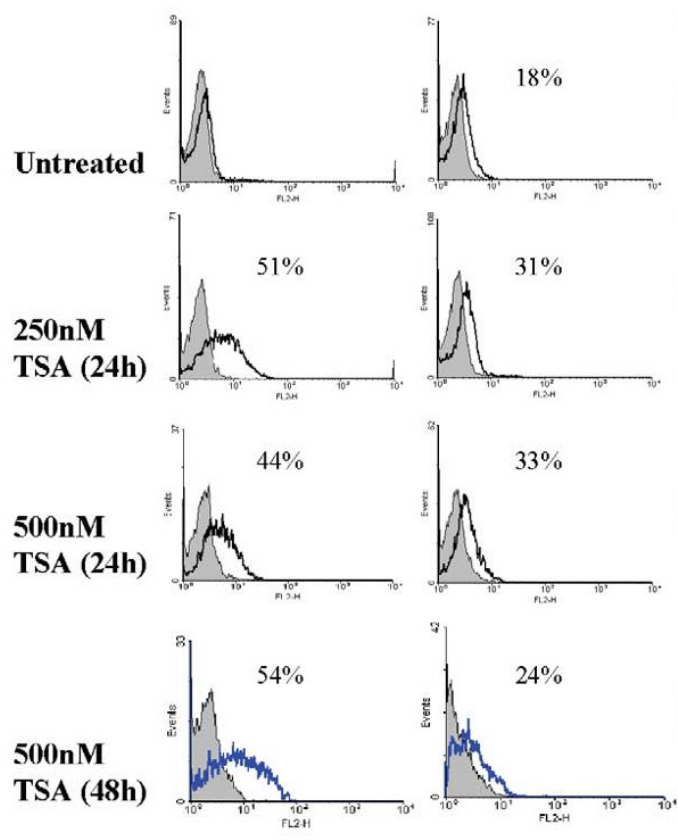

H-2D
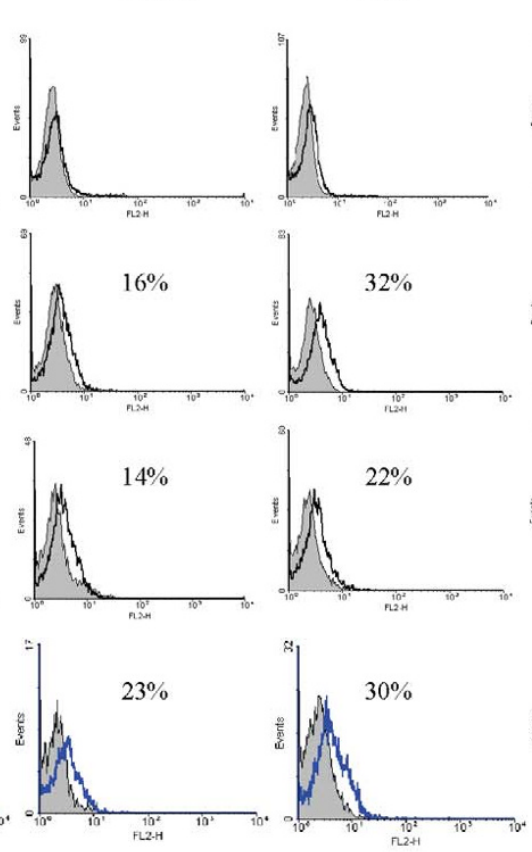

CD40

Annexin V
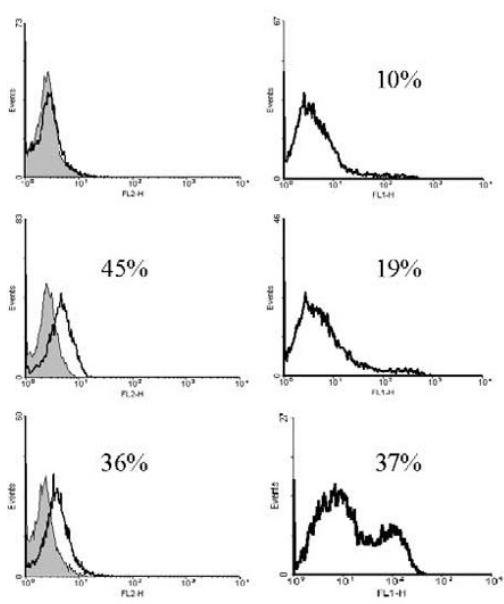

C)
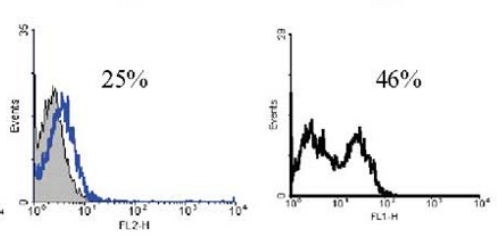

B)

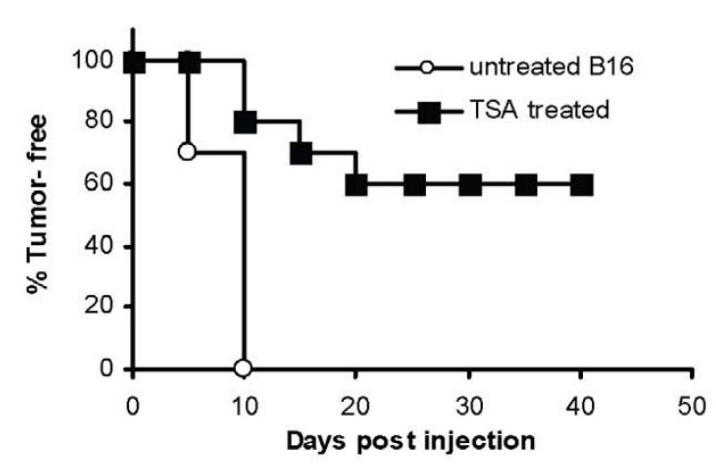

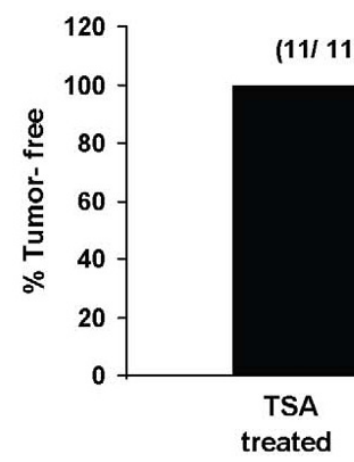

(0/ 10)

Untreated

control

\section{Figure I}

TSA treatment enhances apoptosis and immune gene expression on melanoma cells and TSA-treated vaccines generate immunity. A) BI6 cells were stained with $\mathrm{mAb}$, isotype controls and annexin $\mathrm{V}$ after treatment with TSA and analyzed by flow cytometry for the expression of MHC class I, class II, CD80, CD86 and CD40. Isotype controls are shown as shaded peaks and heavy lines represent expression determined by specific mAb staining. Values indicated in the histograms are the percent of cells positive for the respective $m A b$ relative to the isotype staining. The data presented here are representative of more than three independent experiments. B) Kaplan-Meier plot of B6 mice ( 10 in each group) inoculated with TSA-treated ( $500 \mathrm{nM}$ for $48 \mathrm{~h}$ ) or untreated B 16 cells in the trunk. C) Durable immunity in 100\% of the immune animals. Tumor-free mice, 40 days after vaccination with TSA-treated BI6, were re-challenged with untreated B 6 cells and observed for another 60 days. The number of tumor-free mice compared to total numbers used in each treatment group is shown in parentheses. 
Table I: Tumorigenesis in the epigenetic melanoma vaccine model

\begin{tabular}{lccc}
\hline Treatment & \% AnnexinV ${ }^{+}$cells/inocula & $\begin{array}{c}\text { Number of mice that } \\
\text { developed tumor (total) }\end{array}$ & \% Tumor-free mice after 40 days \\
\hline Untreated & $\sim 10$ & $32(33)$ & 3 \\
$250 \mathrm{nM}$ TSA $(24 \mathrm{~h})$ & $\sim 20$ & $9(10)$ & 10 \\
$500 \mathrm{nM}$ TSA $(24 \mathrm{~h})$ & $\sim 40$ & $7(10)$ & 30 \\
$500 \mathrm{nM}$ TSA (48 h) & $\sim 50$ & $19(48)$ & 61 \\
\hline
\end{tabular}

a TSA-treated (concentrations and length of treatment as indicated) or untreated BI6 cells $\left(\mathrm{I} \times 10^{5}\right.$ trypan blue negative adherent cells) were inoculated s.c. in B6 mice. b The total number of mice used per treatment group is shown in parentheses.

nized with TSA-treated B16 and challenged with untreated tumor cells showed significant increases in the numbers of IFN- $\gamma$-producing cells after B16 cell lysate or mgp $100_{25-}$ ${ }_{33}$ peptide stimulation compared to splenocytes derived from naive mice. The number of IFN- $\gamma$-producing cells found in splenocytes isolated from B16 tumor-bearing mice was significantly lower than the immune mice. PMA/Ionomycin treatment induced a high number of IFN- $\gamma$-producing cells in splenocytes isolated from naïve, tumor-bearing and immune mice. The presence of cytotoxic and IFN- $\gamma$-producing cells in the spleens of immune mice, together with the demonstration of long-term immunity after vaccination with TSA-treated B16 cells, suggest that epigenetically altered tumor cells are capable of inducing cell mediated tumor specific effectors and immunity.

\section{Involvement of $\mathrm{CD4}^{+}, \mathrm{CD}^{+} \mathrm{T}$ cells and $\mathrm{NK}$ cells in immunity induced by epigenetic vaccine}

To determine the role of $\mathrm{CD}^{+}$and $\mathrm{CD} 4{ }^{+} \mathrm{T}$ cells in immunity, MHC double knockout class $\mathrm{I} /-\mathrm{II}-$ - and single knockout class $\mathrm{I}^{-}$- or class $\mathrm{II} /$-mice were used in tumorigenesis experiments, since these MHC disrupted mice lack the related subset of mature T cells (data not shown) [23]. The incidence of tumor rejection in class $\mathrm{I} \%-\mathrm{II} /$, class $\mathrm{I} /$ - and class $\mathrm{II}^{-}-$mice (Figure $2 \mathrm{C}-11 \%, 11 \%, 31 \%$ tumor-free respectively) 40 days after TSA-treated B16 inoculation, is significantly lower than in immunocompetent $\mathrm{B} 6$ mice (73\% tumor-free). Although, the percentage of tumor-free mice in the class II- group is numerically higher than the class $\mathrm{I}^{-/}$group, the difference was not statistically significant ( $\mathrm{p}=0.08)$. In subsequent re-challenge with untreated B16, all the MHC deficient mice developed tumors (data not shown) while immunocompetent mice remained tumor-free.

To more specifically evaluate the contribution of $\mathrm{T}$ cell subsets to protective immunity generated by TSA-treated tumor cell vaccination, in vivo depletion was performed. Calculation of the total number of $\mathrm{CD} 4^{+}$and $\mathrm{CD} 8^{+} \mathrm{T}$ cells in each spleen, isolated from the respective T cell depleted mice, compared to undepleted control spleens, demonstrated $>95 \%$ depletion of specific subsets (data not shown). Figure 2D shows that the percentage of tumor- free mice in $\mathrm{CD}^{+}{ }^{+}$or $\mathrm{CD} 4^{+} \mathrm{T}$ cell depleted groups $(12.5 \%$ and $37.5 \%$, respectively), 3 weeks after vaccination with TSA-treated B16 cells, is significantly lower than the control groups ( $75 \%)$. NK cells can be responsible for tumor rejection by direct lysis of tumor cells and by producing cytokines that recruit and activate DCs and T cells $[24,25]$. Depletion of NK cells prior to vaccination, as shown in Figure 2D, completely abrogated the anti-tumor effect of TSA-treated B16 vaccination. These results demonstrate that $\mathrm{CD} 4^{+}, \mathrm{CD} 8^{+} \mathrm{T}$ cells and NK cells are all required for generation of the immune response by TSA-treated B16 cells and that NK cells are particularly important in tumor rejection. However, the TSA-treated B16 tumorigenesis data from $\mathrm{T}$ cell deficient class $\mathrm{I} /-\mathrm{II}-\mathrm{-}$ - mice and our previous studies in SCID mice with TSA-treated plasmacytoma [4] suggest that NK cells alone, in the absence of T cells, are not sufficient to induce effective anti-tumor immunity in these epigenetic vaccine models.

\section{Antigen presentation by TSA treated tumor cells in vitro and in vivo}

In order to determine the mechanism of epigenetic vaccine induced immunity, we further explored whether B16 melanoma cells are converted to APC following TSA treatment. Figure 3A demonstrates that TSA-treated B16 cells can present ova-peptide ${ }_{322-338}$ to OT-II T cells in the context of MHC class II in vitro. In view of these studies and to determine the role of direct antigen presentation in elicitation of the immune response by epigenetic tumor cell vaccination in vivo, we developed MHC double knockout BM (DKO-C) chimeras using class $\mathrm{I}^{-}-\mathrm{-} I \mathrm{I}^{-}-$donors and irradiated $\mathrm{B} 6$ recipients. Control $\mathrm{BM}(\mathrm{B} 6-\mathrm{C})$ chimeras were produced using immunocompetent $\mathrm{B} 6$ donors and irradiated B6 recipients. Both class I and class II expressing APCs were significantly reduced in DKO-C chimeras and they were repopulated with $\mathrm{CD} 4^{+}$and $\mathrm{CD} 8^{+} \mathrm{T}$ cells (see Additional file 1). Since MHC class I and/or class II mediated antigen presentation by BM derived APCs initiates cross priming of $\mathrm{T}$ cells [1], the DKO-C chimeras are expected to have lost the ability to present antigen from cross priming. B6-C chimeras did not show a deficiency in APC MHC expression, were re-populated with T cells (see Additional file 1) and were expected to have intact crosspresentation capability from both MHC pathways. When 


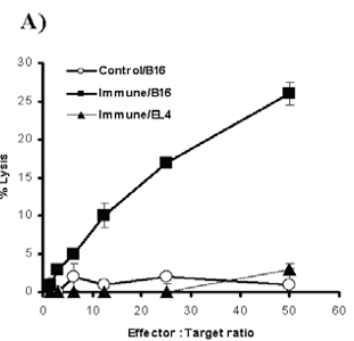

B)
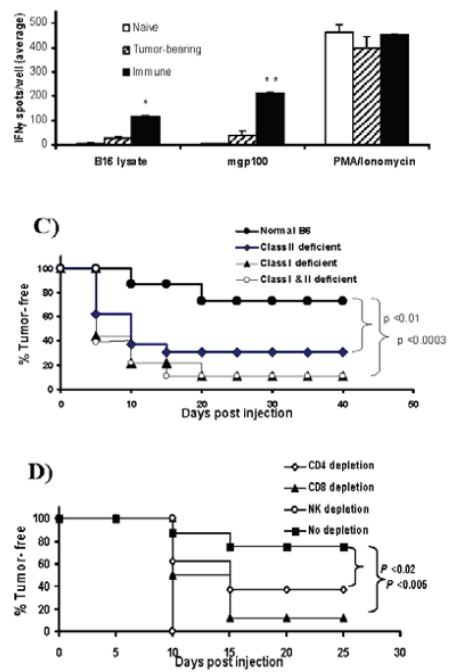

Figure 2

TSA-treated BI6 vaccine elicits cytotoxic and IFN- $\gamma$-producing lymphocytes and requires $\mathrm{T}$ and NK cells in immunity. A) T-cell-enriched splenic lymphocytes isolated from immune or control mice after in vitro re-stimulation were analyzed in triplicate for cytotoxic activity using ${ }^{5 /} \mathrm{Cr}$-labeled untreated B 16 or EL4 as targets. B) Splenocytes isolated from immune, B 16 tumor-bearing or naive B6 mice were cultured in antiIFN- $\gamma$ coated plates with BI 6 cell lysate or melanoma antigen mgp $00_{25-33}$ peptide and IFN- $\gamma$ secretion was detected by ELISpot assay. *, $p<0.0008$ (cell lysate stimulation) and $* *, p$ $<0.03$ (peptide stimulation) compared with splenocytes from tumor-bearing mice. PMA and lonomycin treated splenocytes served as positive control. These experiments ( $A$ and $B$ ) were repeated 3 times with similar results. C) Reduced incidence of TSA-treated (500 nM for 48 h) BI 6 tumor rejection in $\mathrm{MHC}$ deficient mice that lack $\mathrm{CD}^{+}$and/or $\mathrm{CD}^{+}{ }^{+} \mathrm{T}$ cells compared with immunocompetent mice. The Kaplan-Meier plot shows tumor-free survival of class $\mathrm{II}^{-/-}(\mathrm{n}=16)$, class $\mathrm{I}^{-1-}(\mathrm{n}$ $=18)$, class $\mathrm{I}^{-1-}-1 \mathrm{I}^{-1-}(\mathrm{n}=18)$ and immunocompetent $\mathrm{B} 6(\mathrm{n}=15)$ mice after s.c. vaccination with TSA-treated $\mathrm{BI} 6\left(\mathrm{I} \times 10^{5}\right.$ cells). D) Depletion of $\mathrm{CD}^{+}, \mathrm{CD}^{+} \mathrm{T}$ cells and NK cells reduces immunity generation by TSA-treated $\mathrm{B} / 6$ cells. $\mathrm{B} 6$ mice were depleted of $\mathrm{CD}^{+}(n=16), \mathrm{CD}^{+}(n=8)$ T cells or NK cells $(n=8)$ by repeated injection of respective antibodies (see Methods). Undepleted controls $(n=16)$ received IgG. All mice were observed for tumor growth after s.c. vaccination with TSA-treated BI6 cells in the trunk.
A)

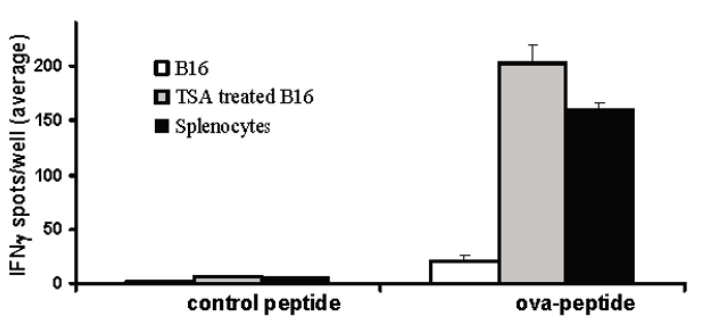

B)

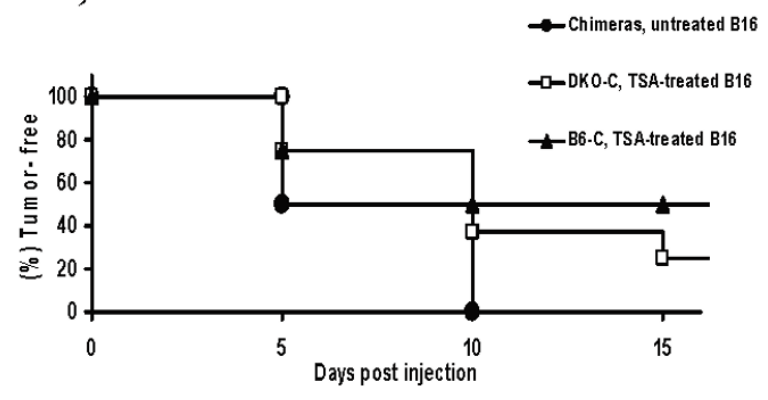

Figure 3

TSA treatment converts BI6 melanoma cells to APCs. A) In vitro antigen presentation by TSA-treated (500 nM for $48 \mathrm{~h}$ ) BI 6 cells. Purified T cells from OT-II mice were cultured with antigen-pulsed (ova-peptide ${ }_{322-338}$ or control peptide), irradiated BI6 cells (TSA-treated or untreated) and splenocytes (from OT-II mice as control APCs) in a standard ELISpot assay to measure IFN- $\gamma$-secreting cells. B) Eight weeks after BM transplantation, control [B6-C] and MHC double knockout [DKO-C] chimeras were inoculated s.c. with TSAtreated $\mathrm{BI} 6\left(\mathrm{I} \times 10^{5}\right.$ cells $)$ in the trunk and tumor-free survival was recorded. Control groups of B6-C and DKO-C chimeras were injected with untreated B 6 cells. The survival curve for these two groups were coincident; therefore a representative plot [chimeras, untreated BI6] showing the tumor-free survival of these controls is presented. Results from two independent experiments (four chimeras/group/ experiment) are presented in this figure.

these chimeras were inoculated with TSA-treated or untreated B16 cells, 50\% of control chimeras and 37.5\% of DKO-C chimeras remained tumor-free 10 days after inoculation of TSA-treated B16 cells while all the B6-C and DKO-C chimeras had developed untreated B16 tumors (Figure 3B). Delayed tumor generation, at day 10, in B6-C $(\mathrm{p}<0.01)$ or DKO-C chimeras $(\mathrm{p}<0.03)$ after inoculation of TSA-treated cells was statistically significant compared to B6-C or DKO-C chimeras injected with untreated B16. These data demonstrate that, in the absence of cross-presentation, tumor generation is delayed suggesting that direct antigen presentation by TSA-treated tumor cells may contribute to delayed tumor 
growth. However, neither control nor MHC deficient chimeras were able to provide the long-term protection after vaccination with TSA-treated B16 cells that was demonstrated by the immunocompetent mice (Figure 1). This observation also suggests that the BM chimeras used for these experiments, although repopulated with T cells, may not be completely immunocompetent as has been noted by others [26]. Additionally, a recent report suggests that direct presentation by TSA-treated B16 cells may generate partial activation of T cell effector function, but is unable to provide long-term protection in the absence of other signals [27]. This may, at least in part, explain the ability in our chimeric experiments to elicit short-term but not long-term immunity.

\section{Role of apoptotic tumor cells in the generation of immunity}

The tumorigenesis studies with B16 cells (Table 1) showed that the highest level of immunity was obtained using vaccine preparations containing apoptotic cells. This raises the possibility that TSA treatment enhances immunity, at least in part, by induction of apoptosis. To further elucidate the role of apoptotic cells in the B16 model and the ratio of apoptotic to viable cells required for optimal immunity, populations of apoptotic and nonapoptotic adherent B16 cells were separated using annexinV magnetic beads. We also compared the effects of TSAapoptotic cells with those elicited by $\mathrm{H}_{2} \mathrm{O}_{2}$, a potent inducer of apoptosis via the oxidative pathway [28]. The dose of $\mathrm{H}_{2} \mathrm{O}_{2}$ was determined by titration of $\mathrm{B} 16$ cells with $\mathrm{H}_{2} \mathrm{O}_{2}$ at various concentrations and incubation times with apoptosis measured by flow cytometry. Flow cytometric analysis of the separated TSA or $\mathrm{H}_{2} \mathrm{O}_{2}$-treated $\mathrm{B} 16$ populations showed that $>99 \%$ of the cells in the apoptotic fraction were $\mathrm{an}^{+}$and $>85 \%$ cells in the non-apoptotic fraction were an- (data not shown). To determine tumorigenicity and immunity, groups of mice were inoculated with TSA or $\mathrm{H}_{2} \mathrm{O}_{2}$-treated apoptotic cells, TSAtreated non-apoptotic or mixed (50\% TSA-treated apoptotic $+50 \%$ TSA-treated non-apoptotic) B16 cells. As shown in Figure 4A, 40\% of mice that received mixed B16 inocula were tumor-free at day 20, while all the mice injected with TSA-treated non-apoptotic or untreated B16 cells developed tumors. TSA or $\mathrm{H}_{2} \mathrm{O}_{2}$-treated apoptotic cells did not replicate in vitro (data not shown) and did not produce tumors in vivo (Figure $4 \mathrm{~A}$ ). To determine the level of immunity induced, all tumor-free mice were challenged after 3 weeks with untreated B16 cells. The TSAtreated live plus apoptotic 50:50 mixture generated a significantly higher level of durable immunity (Figure 4B, $88 \%$ tumor-free) compared to the TSA-treated apoptotic inoculums (30\% tumor-free) and $\mathrm{H}_{2} \mathrm{O}_{2}$-treated apoptotic cells failed to elicit long-term immunity. The lasting immunity induced by TSA-treated apoptotic cells is statistically significant compared to $\mathrm{H}_{2} \mathrm{O}_{2}$-treated apoptotic
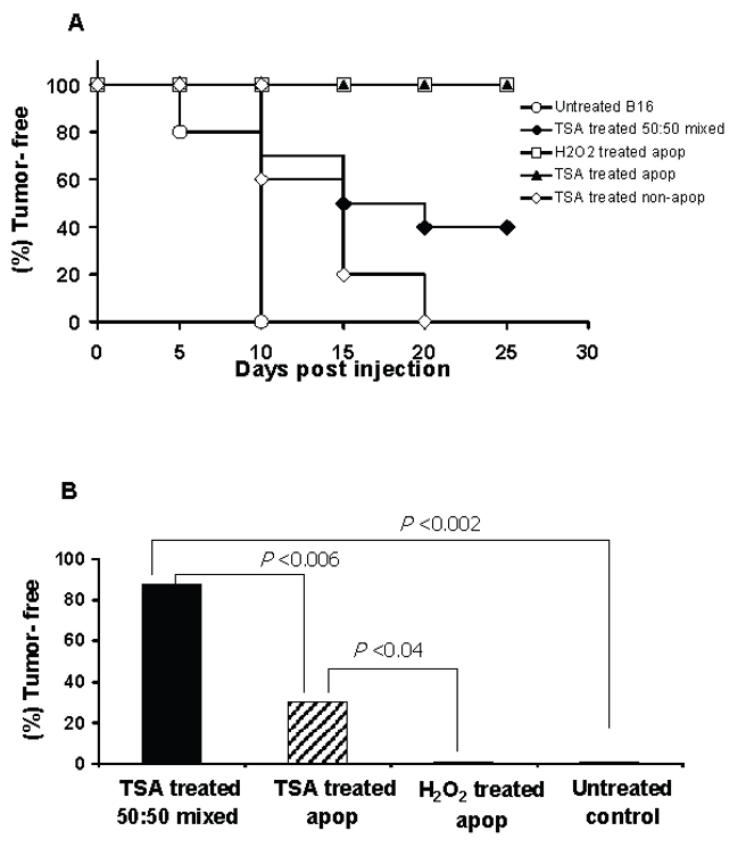

\section{Figure 4}

Anti-tumor immunity generated by TSA-treated apoptotic BI 6 cells. A) Kaplan-Meier plot of B6 mice ( 10 mice/group) vaccinated s.c. with magnetically separated TSA-treated (500 nM for $48 \mathrm{~h}$ ) apoptotic $\left(-99 \% \mathrm{an}^{+}\right)$, non-apoptotic (>85\% an), mixed (50\% an ${ }^{+}$with $50 \%$ an-) or $\mathrm{H}_{2} \mathrm{O}_{2}$-treated ( $10 \mathrm{mM}$ for $4 \mathrm{~h})$ apoptotic $\left(\sim 99 \% \mathrm{an}^{+}\right) \mathrm{BI} 6\left(\mathrm{I} \times 10^{5}\right.$ cells) and observed for tumor-free survival. Control mice received untreated BI 6 cells. B) Tumor-free mice, 3 weeks after vaccination with TSA-treated apoptotic $(n=10)$, non-apoptotic $(n=8)$, mixed $(n=8)$ or $\mathrm{H}_{2} \mathrm{O}_{2}$-treated apoptotic $(n=10)$ BI 6 cells were re-challenged with untreated $\mathrm{BI} 6\left(\mathrm{I} \times 10^{5}\right.$ cells $)$ s.c. in the opposite side of the trunk and observed subsequently for another 6 weeks. The data are presented as the percentage of tumor-free mice after tumor challenge.

cells and untreated controls ( $\mathrm{p}<0.04)$. These data suggest that TSA-treated apoptotic cells may play a role in immunity and TSA-treated preparations containing 50\% apoptotic cells, in addition to non-apoptotic cells, are most effective in inducing long-term immunity. Importantly, these data also suggest that generation of durable immunity by annexinV positive tumor cells may vary depending on the apoptosis-inducing agents [28].

Treatment with epigenetically altered melanoma vaccines suppresses growing tumors

To evaluate the potential of clinical translation of the TSAtreated vaccine model, two sets of tumorigenesis experiments were performed. Firstly, to eliminate tumor growth from the vaccine inocula, we lethally irradiated tumor cells before inoculation and found that $100 \%$ of the mice 
injected with TSA-treated or untreated B16 cells (irradiated) did not develop tumor (data not shown). After 3 weeks, tumor-free mice from both groups were challenged with wild type B16; $50 \%$ of the TSA-radiation group and only $12.5 \%$ of the control-radiation group showed durable immunity (Figure 5A). These data suggest that killing the TSA-treated tumor cells with radiation does not reduce the vaccine efficacy. Additionally, to determine the efficacy of the irradiated vaccine in a therapeutic model, palpable B16 tumor-bearing mice were inoculated with TSAtreated or untreated $\mathrm{B} 16$ cells (irradiated) on the opposite side. As shown in Figure 5B and 5C, 100\% of mice receiving a single injection of TSA-treated (irradiated) B16 vaccine were tumor-free at 42 days and $50 \%$ of them remained tumor-free 40 days after wild type tumor challenge. In $75 \%$ of tumor-bearing mice, the tumor regressed after injection with irradiated B16 cells (Figure 5B), but none of them were protected against challenge with wild type B16 (Figure 5C). These data demonstrate that vaccination with TSA-treated (irradiated) tumor cells can suppress primary tumor growth as well as promote long-term immunity in this treatment model.

\section{Discussion}

This study demonstrates that vaccination with TSA-treated melanoma cells expressing both MHC class II and costimulatory molecules can generate tumor-specific durable immunity and that the vaccine is effective against an existing B16 tumor in a treatment protocol. The induction of tumor immunity described here requires $\mathrm{CD} 8^{+}, \mathrm{CD} 4^{+} \mathrm{T}$ and NK cells. Experiments performed in MHC class I knockouts and $\mathrm{CD} 8^{+} \mathrm{T}$ cell antibody-depleted mice substantially reduced the anti-tumor effects of the vaccine thereby supporting the essential role of $\mathrm{CD}^{+} \mathrm{T}$ cells in this model. Additionally, the partial abrogation of the immune responses in class II knockout mice, the lack of immunity in MHC double knockout mice and the tumorigenesis data in $\mathrm{CD} 4^{+} \mathrm{T}$ cell antibody-depleted animals suggest that $\mathrm{CD} 4^{+} \mathrm{T}$ cells are also essential in the generation of immunity. The data from $\mathrm{T}$ cell deficient or depleted mice together with the findings of cytotoxic and IFN- $\gamma$-secreting lymphocytes in immune mice in association with long term immunity demonstrate that a single dose of the TSA-treated tumor cell vaccine is capable of activating naïve $\mathrm{T}$ cells to generate cytotoxic effector and memory T cells. Our results also showed that depletion of NK cells completely abrogated immunity generation by TSA-treated B16 cells suggesting that NK cells, together with T cells, play an important role in initiation of immunity following epigenetic vaccination.

The association of immunity with enhanced class II and costimulatory molecule expression and in vitro activation of antigen-specific CD4 ${ }^{+} \mathrm{T}$ cells by TSA-treated melanoma cells is consistent with the hypothesis of direct antigen

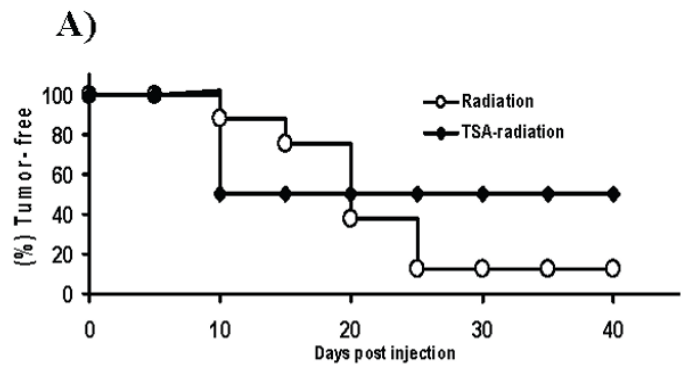

B)
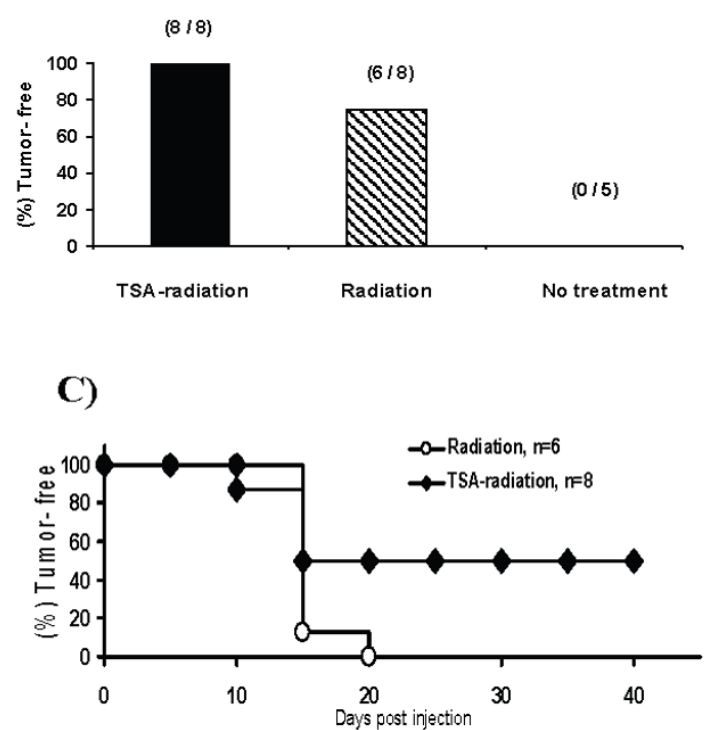

Figure 5

Prevention and treatment of melanoma by TSA-treated (irradiated) tumor cell vaccine. A) Vaccination with TSA-treated (500 nM for $48 \mathrm{~h}$ ) and irradiated (2000 Gy) BI 6 cells prevents $B \mid 6$ tumor generation. Three weeks after s.c. inoculation of TSA-treated [TSA-radiation] or untreated [radiation] $\mathrm{BI} 6\left(\mathrm{I} \times 10^{5}\right)$ cells in B6 mice ( 16 in each group); all tumorfree mice were challenged s.c. with wild type BI6 $\left(I \times 10^{5}\right)$ cells and observed for 40 days. Percentage of tumor-free mice is presented in the Kaplan-Meier plot. B) Suppression of primary tumor growth by TSA-treated and irradiated melanoma vaccine. Groups of B6 mice bearing palpable BI6 ( 5 days tumor growth) were treated s.c. with TSA-treated and irradiated B 6 [TSA-radiation] or untreated irradiated BI6 ( $1 \times 10^{5}$ cells) [radiation] in the opposite side of the trunk. A group of tumor-bearing mice did not receive any treatment [no treatment]. The number of tumor-free mice compared to total numbers used in each group is shown in parentheses at $\mathbf{4 2}$ days after treatment. C) Induction of longterm immunity in tumor-bearing mice treated with epigenetically altered melanoma vaccine. BI 6 tumor-bearing mice that became tumor-free following vaccine treatment were rechallenged s.c. with wild type BI6 ( $\times 10^{5}$ cells). KaplanMeier plot shows tumor-free survival of mice in both TSAradiation and radiation groups after re-challenge. 
presentation by tumor cells in vivo. That direct presentation could be a component of tumor immunity is suggested by: 1) the reported demonstration of direct presentation in viral and other tumor model systems $[7,29] ; 2)$ the effectiveness of tumor vaccines established by transfecting tumor cells with $\mathrm{MHC}$ and costimulatory genes [30]; and 3) the conversion of tumor cells to APCs by epigenetic agents discussed above and previously reported $[14,18]$. The substantial effectiveness of the TSAmodified tumor cell vaccine shown here, together with the delayed tumor generation data in MHC deficient chimeras, suggest a short-lived in vivo effect from direct antigen presentation. Our view is that cross-presentation is likely the major mechanism of $\mathrm{T}$ cell activation in most tumors (as outlined by others and reviewed in [2]) but that, in certain tumors and conditions, a component of direct presentation may exist. The important issue is whether clinically significant direct presentation can be established by appropriate treatments designed to convert a sizable portion of the tumor cells in the tumor bed to APCs. Since tumors may have a billion or more cells when first detected [31], converting even a small percentage of cells could potentially have significant effects. Furthermore, we would expect that Treg cells and other immunosuppressive mechanisms might also repress direct presentation. It remains to be determined whether combinations of the epigenetic vaccine with other modalities, such as adjuvants or anti-Treg antibody, can enhance the efficacy of direct antigen presentation by tumors. Current evidence suggests that sustained antigen presentation is important in promoting immunity and that the duration of antigen presentation is a major factor in activation of memory T cells $[32,33]$. The short-term effects seen in vivo in the direct presentation model could reflect the lack of sustained antigen presentation. Further experiments are required that include multiple injections, adjuvants with sustained antigen release, further adjustments of amount and concentration of the apoptotic population and other procedures employed for DC vaccines directed at enhancing and maintaining MHC/peptide complex and maintaining the adjuvant environment and activation state of the tumor $[33,34]$.

Since HDACi affect the expression of many genes [12], we consider it likely that additional mechanisms other than direct presentation may contribute to epigenetically induced tumor immunity. In this regard, TSA treatment can enhance the expression of NKG2D ligands [35] on tumor cells, which may activate NK cell mediated immune responses and synergize with CD28 in inducing proliferation and IFN- $\gamma$ production by CD8+ T cells [36]. However, whether TSA induction of NKG2D ligands is mediated by chromatin or stress effects on tumor cells is uncertain. In addition, although our data and other reports suggest that $\mathrm{NK}$ cells can mediate immunity against tumor cells expressing NKG2D ligand [37] or MHC class I [38], the role of NK cells in generating a longlasting memory immune response after epigenetic vaccination is uncertain. One possibility suggested by the strict requirement for NK cells is that NK cells interact with tumor cells treated with TSA (and expressing CD40) as described for DC $[39,40]$ and enhance antigen presentation [33].

Apoptotic tumor cells could potentially contribute to immunity generation through several pathways. Previous studies suggested that phagocytosis of apoptotic cells by DCs in certain conditions can induce tolerance [41], while other reports demonstrate that cross-presentation of antigen from apoptotic tumor cells can generate tumor specific immune responses [42]. The experiments performed with TSA-treated apoptotic B16 preparations demonstrated that apoptotic tumor cells are capable of eliciting long-term immunity. The induction of immunity by apoptotic tumor cells has been related to their ability to induce inflammation and to mature DC, in part owing to the presence of heat shock proteins in apoptotic cell preparations, especially those containing necrotic cells $[1,43,44]$. Since apoptotic cells were defined by annexinV binding in our study, the presence of $\mathrm{an}^{+}$necrotic cells is likely in TSA-treated apoptotic preparations. It has been reported that apoptotic tumor cells produced by treatment with TSA have different expression patterns of MHC class II and costimulatory molecules compared to apoptotic cells elicited by L-phenylalanine mustard, $\mathrm{H}_{2} \mathrm{O}_{2}$ and $\gamma$-irradiation [28]. Moreover the data presented here shows that apoptotic tumor cell preparations produced by TSA, but not $\mathrm{H}_{2} \mathrm{O}_{2}$, treatment generated long-term immunity. The failure of the $\mathrm{H}_{2} \mathrm{O}_{2}$-treated apoptotic $\mathrm{B} 16$ cells to enhance immunity demonstrates a selective effect of TSAtreated apoptotic cells and suggests that apoptosis inducing agents should be carefully evaluated for differential effects in anti-cancer therapy. In this regard, recent evidence suggests that apoptotic cell death due to caspase- 3 activation results in the release of bioactive lipid molecules, which promote DC maturation and pro-inflammatory responses [45]. Since TSA may induce apoptosis in certain tumor cells through a caspase- 3 and mitochondria dependent pathway [46], it is possible that TSA-treated apoptotic B16 cells release bioactive lipids, which promote innate, perhaps TLR and NK mediated, immunity as well as adaptive responses.

The reported enhancement of DC vaccine potency by the addition of apoptosis promoting agents suggests a role for apoptotic cells in synergizing with live cells in eliciting immunity [47]. Our results showed that addition of TSAtreated non-apoptotic cells to apoptotic (50\% an- $+50 \%$ $\mathrm{an}^{+}$) B16 inocula significantly improved the vaccine efficacy. Therefore, in addition to the conversion of tumor 
cells to APCs, the combination of replicating tumor cells producing high levels of antigen with an apoptotic adjuvant-like effect could explain the superiority of the high dose $(500 \mathrm{nM}$ ) TSA-treated $\mathrm{B} 16$ vaccines compared with lower doses of TSA and the $\mathrm{H}_{2} \mathrm{O}_{2}$-treated cells. Also, since TSA alters chromatin and indirectly inhibits DNA methylation [48], it could potentially activate repressed endogenous tumor antigens, such as MAGE [49] and HMWMAA [50] that may serve as epigenetically induced tumor antigens. Finally, HDACi modulates DNA damage (ATM/ ATR) [35] and MAPK pathways [51] and could therefore serve as an intracellular adjuvant, which have been shown to enhance DC vaccine potential [34].

The data presented here suggests that an autologus tumor cell vaccine generated by HDACi in vitro is effective in both preventative and treatment models. Further work, currently in progress, will focus on obtaining more effective vaccines using different HDACi preparations, combination with adjuvant or anti-Treg as well as multiple vaccinations. We would envision future clinical protocols using this vaccine, most likely in combination with surgery and/or other strategies, to treat recurrence and metastasis of tumors. Clearly there are challenges and potential problems in adapting a cell-based vaccine of this type to the treatment of human cancer. If clinically effective vaccines could be developed, they would have the advantage of being histocompatible with the host and applicable without prior knowledge of the tumor antigens involved. These studies also suggest that current therapies with epigenetic agents could affect host immunity to the tumor and attention should be given to this aspect in ongoing and future clinical protocols using these agents systemically.

\section{Competing interests}

The author(s) declare that they have no competing interests.

\section{Authors' contributions}

A. Nazmul H. Khan - had the primary responsibility for designing and conducting all the experiments, data analysis and initial drafting of the manuscript; William J. Magner - was involved in study design, drafting and review of the manuscript; Thomas B. Tomasi - conceived the study, contributed to the design and subsequent drafts of the manuscript. All authors read and approved the final manuscript.

\section{Additional material}

\section{Additional File 1}

Characterization of lymphocyte re-constitution in bone marrow chimeras. The data provided characterize lymphocyte reconstitution in the chimeras by flow cytometric analysis of peripheral blood lymphocytes isolated from chimeras.

Click here for file

[http://www.biomedcentral.com/content/supplementary/14795876-5-64-S1.pdf]

\section{Acknowledgements}

Supported by National Institutes of Health grant HD I70I3 and utilized core facilities of Roswell Park Cancer Institute's NCI Cancer Center Support Grant CAI6056.

\section{References}

I. Restifo NP: Building better vaccines: how apoptotic cell death can induce inflammation and activate innate and adaptive immunity. Curr Opin Immunol 2000, I 2(5):597-603.

2. Heath WR, Carbone FR: Cross-presentation, dendritic cells, tolerance and immunity. Annu Rev Immunol 200I, 19:47-64.

3. Nowak AK, Lake RA, Marzo AL, Scott B, Heath WR, Collins EJ, Frelinger JA, Robinson BW: Induction of tumor cell apoptosis in vivo increases tumor antigen cross-presentation, crosspriming rather than cross-tolerizing host tumor-specific CD8 T cells. J Immunol 2003, I 70( I 0):4905-49I3.

4. Khan AN, Magner WJ, Tomasi TB: An epigenetically altered tumor cell vaccine. Cancer Immunol Immunother 2004, 53(8):748-754.

5. Qi L, Rojas JM, Ostrand-Rosenberg S: Tumor cells present MHC class II-restricted nuclear and mitochondrial antigens and are the predominant antigen presenting cells in vivo. J Immunol 2000, I 65(1 0):545I-546I.

6. Knutson KL, Disis ML: Tumor antigen-specific $\mathbf{T}$ helper cells in cancer immunity and immunotherapy. Cancer Immunol Immunother 2005, 54(8):72I-728.

7. Schoenberger SP, Jonges LE, Mooijaart RJ, Hartgers F, Toes RE, Kast WM, Melief CJ, Offringa R: Efficient direct priming of tumorspecific cytotoxic $T$ lymphocyte in vivo by an engineered APC. Cancer Res 1998, 58( I 4):3094-3100.

8. Pulaski BA, Ostrand-Rosenberg S: Reduction of established spontaneous mammary carcinoma metastases following immunotherapy with major histocompatibility complex class II and B7.I cell-based tumor vaccines. Cancer Res 1998, 58(7): | 486-|493.

9. Mortara L, Castellani P, Meazza R, Tosi G, De Lerma Barbaro A, Procopio FA, Comes A, Zardi L, Ferrini S, Accolla RS: CIITA-induced MHC class II expression in mammary adenocarcinoma leads to a ThI polarization of the tumor microenvironment, tumor rejection, and specific antitumor memory. Clin Cancer Res 2006, I 2( I | Pt I):3435-3443.

10. Jabrane-Ferrat N, Campbell MJ, Esserman LJ, Peterlin BM: Challenge with mammary tumor cells expressing MHC class II and CD80 prevents the development of spontaneously arising tumors in MMTV-neu transgenic mice. Cancer Gene Ther 2006, I3(II): 1002-1010.

II. Marincola FM, Jaffee EM, Hicklin DJ, Ferrone S: Escape of human solid tumors from $T$-cell recognition: molecular mechanisms and functional significance. Adv Immunol 2000, 74: I8I-273.

12. Tomasi TB, Magner WJ, Khan AN: Epigenetic regulation of immune escape genes in cancer. Cancer Immunol Immunother 2006, 55(10): II59-II84.

13. Magner WJ, Kazim AL, Stewart C, Romano MA, Catalano G, Grande C, Keiser N, Santaniello F, Tomasi TB: Activation of MHC class I, II, and CD40 gene expression by histone deacetylase inhibitors. J Immunol 2000, I65( I 2):7017-7024. 
14. Khan AN, Gregorie CJ, Tomasi TB: A role for chromatin in the regulation of TAP, LMP, Tapasin genes and MHC class I antigen presentation. Cancer Immunol Immunother in press.

15. Jenuwein T, Allis CD: Translating the histone code. Science 200I, 293(5532): 1074-1080.

16. Mariadason JM, Corner GA, Augenlicht LH: Genetic reprogramming in pathways of colonic cell maturation induced by short chain fatty acids: comparison with trichostatin $A$, sulindac, and curcumin and implications for chemoprevention of colon cancer. Cancer Res 2000, 60( I 6):456I-4572.

17. Marks PA, Richon VM, Breslow R, Rifkind RA: Histone deacetylase inhibitors as new cancer drugs. Curr Opin Oncol 200I, 13(6):477-483.

18. Chou SD, Khan AN, Magner WJ, Tomasi TB: Histone acetylation regulates the cell type specific CIITA promoters, MHC class II expression and antigen presentation in tumor cells. Int Immunol 2005, I7( I I): I 483-I494.

19. Manjili MH, Wang XY, Chen X, Martin T, Repasky EA, Henderson R, Subjeck JR: HSPIIO-HER2/neu chaperone complex vaccine induces protective immunity against spontaneous mammary tumors in HER-2/neu transgenic mice. J Immunol 2003, I 7 I(8):4054-406I.

20. Sotomayor EM, Borrello I, Rattis FM, Cuenca AG, Abrams J, StaveleyO'Carroll K, Levitsky HI: Cross-presentation of tumor antigens by bone marrow-derived antigen-presenting cells is the dominant mechanism in the induction of T-cell tolerance during B-cell lymphoma progression. Blood 200I, 98(4): 1070-1077.

21. Lenz LL, Butz EA, Bevan MJ: Requirements for bone marrowderived antigen-presenting cells in priming cytotoxic $T$ cell responses to intracellular pathogens. J Exp Med 2000, | 92(8): I I35-I | 42.

22. Nonacs RM, Witmer-Pack MD, Steinman RM: Enrichment of dendritic cells by plastic adherence and EA Rosetting. Current Protocols in Immunology 1992:3.7.1.

23. Grusby MJ, Glimcher LH: Immune responses in MHC class IIdeficient mice. Annu Rev Immunol 1995, 13:4I 7-435.

24. Degli-Esposti MA, Smyth MJ: Close encounters of different kinds: dendritic cells and NK cells take centre stage. Nat Rev Immunol 2005, 5(2): I I 2-124.

25. Hamerman JA, Ogasawara K, Lanier LL: NK cells in innate immunity. Curr Opin Immunol 2005, I 7(I):29-35.

26. Vallera DA, Soderling CC, Orosz CG: Assessment of immunocompetence by limiting dilution analysis in long-term $\mathrm{T}$ cell depletion chimeras transplanted across the MHC barrier. Transplantation 1985, 40(3):3|I-3|6.

27. Hargadon KM, Brinkman CC, Sheasley-O'neill SL, Nichols LA, Bullock $\mathrm{TN}$, Engelhard $\mathrm{VH}$ : Incomplete differentiation of antigen-specific CD8 T cells in tumor-draining lymph nodes. J Immunol 2006, I 77(9):608I-6090.

28. Magner WJ, Tomasi TB: Apoptotic and necrotic cells induced by different agents vary in their expression of MHC and costimulatory genes. Mol Immunol 2005, 42(9): I033-1042.

29. Brady MS, Eckels DD, Ree SY, Schultheiss KE, Lee JS: MHC class IImediated antigen presentation by melanoma cells. J Immunother Emphasis Tumor Immunol 1996, 19(6):387-397.

30. Ostrand-Rosenberg S, Pulaski BA, Clements VK, Qi L, Pipeling MR, Hanyok LA: Cell-based vaccines for the stimulation of immunity to metastatic cancers. Immunol Rev 1999, I70:101-1 I4.

31. Friberg S, Mattson S: On the growth rates of human malignant tumors: implications for medical decision making. J Surg Oncol 1997, 65(4):284-297.

32. lezzi $G$, Karjalainen $K$, Lanzavecchia $A$ : The duration of antigenic stimulation determines the fate of naive and effector $T$ cells. Immunity 1998, 8(1):89-95.

33. Obst R, van Santen HM, Melamed R, Kamphorst AO, Benoist C, Mathis $D$ : Sustained antigen presentation can promote an immunogenic $\mathbf{T}$ cell response, like dendritic cell activation. Proc Natl Acad Sci USA 2007, 104(39): 15460-15465.

34. Andreakos E, Williams RO, Wales J, Foxwell BM, Feldmann M: Activation of NF-kappaB by the intracellular expression of NFkappaB-inducing kinase acts as a powerful vaccine adjuvant. Proc Natl Acad Sci USA 2006, I 03(39): 14459- 14464.

35. Gasser S, Orsulic S, Brown EJ, Raulet DH: The DNA damage pathway regulates innate immune system ligands of the NKG2D receptor. Nature 2005, 436(7054): I I86-I 190.
36. Ehrlich LI, Ogasawara K, Hamerman JA, Takaki R, Zingoni A, Allison JP, Lanier LL: Engagement of NKG2D by cognate ligand or antibody alone is insufficient to mediate costimulation of human and mouse CD8+ T cells. I Immunol 2005, 174(4): $1922-1931$.

37. Zhou H, Luo Y, Lo JF, Kaplan CD, Mizutani M, Mizutani N, Lee JD, Primus FJ, Becker JC, Xiang R, et al.: DNA-based vaccines activate innate and adaptive antitumor immunity by engaging the NKG2D receptor. Proc Natl Acad Sci USA 2005, I02(3I): |0846-1085|

38. Kamiryo $Y$, Yajima T, Saito K, Nishimura H, Fushimi T, Ohshima $Y$, Tsukamoto $Y$, Naito S, Yoshikai Y: Soluble branched $(1,4)$-betaD-glucans from Acetobacter species enhance antitumor activities against MHC class I-negative and -positive malignant melanoma through augmented NK activity and cytotoxic T-cell response. Int J Cancer 2005, I I 5(5):769-776

39. Walzer T, Dalod M, Robbins SH, Zitvogel L, Vivier E: Natural-killer cells and dendritic cells: "I'union fait la force". Blood 2005, I06(7):2252-2258.

40. Munz C, Steinman RM, Fujii S: Dendritic cell maturation by innate lymphocytes: coordinated stimulation of innate and adaptive immunity. J Exp Med 2005, 202(2):203-207.

4I. Steinman RM, Turley S, Mellman I, Inaba K: The induction of tolerance by dendritic cells that have captured apoptotic cells. J Exp Med 2000, I 9 I(3):4II-4I6.

42. Nouri-Shirazi M, Banchereau J, Bell D, Burkeholder S, Kraus ET, Davoust J, Palucka KA: Dendritic cells capture killed tumor cells and present their antigens to elicit tumor-specific immune responses. J Immunol 2000, 165(7):3797-3803.

43. Basu S, Binder RJ, Suto R, Anderson KM, Srivastava PK: Necrotic but not apoptotic cell death releases heat shock proteins, which deliver a partial maturation signal to dendritic cells and activate the NF-kappa B pathway. Int Immunol 2000, I2(II):1539-1546.

44. Inaba K, Turley S, Yamaide F, lyoda T, Mahnke K, Inaba M, Pack M, Subklewe M, Sauter B, Sheff D, et al.: Efficient presentation of phagocytosed cellular fragments on the major histocompatibility complex class II products of dendritic cells. J Exp Med 1998, I 88(II):2163-2173.

45. Albert ML: Death-defying immunity: do apoptotic cells influence antigen processing and presentation? Nat Rev Immunol 2004, 4(3):223-231.

46. Roh MS, Kim CW, Park BS, Kim GC, Jeong JH, Kwon HC, Suh DJ, Cho KH, Yee SB, Yoo YH: Mechanism of histone deacetylase inhibitor Trichostatin A induced apoptosis in human osteosarcoma cells. Apoptosis 2004, 9(5):583-589.

47. Candido KA, Shimizu K, McLaughlin JC, Kunkel R, Fuller JA, Redman BG, Thomas EK, Nickoloff BJ, Mule J]: Local administration of dendritic cells inhibits established breast tumor growth: implications for apoptosis-inducing agents. Cancer Res 200I, 6 I (I):228-236.

48. Bestor TH: Gene silencing. Methylation meets acetylation. Nature 1998, 393(6683):3। |-3।2.

49. Wischnewski F, Pantel K, Schwarzenbach H: Promoter demethylation and histone acetylation mediate gene expression of MAGE-AI, -A2, -A3, and -AI 2 in human cancer cells. Mol Cancer Res 2006, 4(5):339-349.

50. Luo W, Wang X, Kageshita T, Wakasugi S, Karpf AR, Ferrone S: Regulation of high molecular weight-melanoma associated antigen (HMW-MAA) gene expression by promoter DNA methylation in human melanoma cells. Oncogene 2006, 25(20):2873-2884.

5I. Yu C, Friday BB, Lai JP, McCollum A, Atadja P, Roberts LR, Adjei AA: Abrogation of MAPK and Akt signaling by AEE788 synergistically potentiates histone deacetylase inhibitor-induced apoptosis through reactive oxygen species generation. Clin Cancer Res 2007, I3(4): I | 40- I | 48. 